\title{
Cognitive Foundation of Diversity Management: Bridging the Gap between Aspiration and Reality
}

\author{
Jie G. McCardle \\ Georgia Southern University \\ Sandra S. Speck \\ Idaho State University
}

Lewin's change model states that the most effective way to implement a change is to reduce restraining forces. In this article, we suggest that cognitive biases are a major restraining force that has been ignored in diversity management research. Drawing upon the theory of rationality/intuition two-system thinking, we explain that the driving forces for workforce diversity are primarily propelled by rational reasoning. Yet, their effects are impeded by the cognitive roadblocks rooted in intuitive thinking. We propose a behavioral design approach to reduce the restraining forces by mitigating perceptual biases and judgment errors in the work context.

Keywords: Diversity Management, Behavioral Design, Rationality and Intuition, Cognitive Model, Change Theory

\section{INTRODUCTION}

Diversity management refers to organizational processes designed to create greater inclusion of employees from various backgrounds through deliberate policies and programs (Ivancevich \& Gilbert, 2000). Corporate America has embraced diversity as one of the essential changes undertaken in the modern era. This endeavor is evidenced by the billions of dollars companies spend on diversity and inclusion training every year, as well as a rapid increase in academic research that spans many disciplines and levels (Konrad, Prasad, \& Pringle, 2005).

The term "diversity" broadly refers to differences among individuals, ranging from objective characteristics such as race, gender, age, and physical features to subjective attributes such as value, personality, professional identity, ideology, and socioeconomic status (Konrad et al., 2005). In this article, workplace diversity focuses on the differences that induce discrimination, as discussed in the management literature. Reflecting on the very nature of diversity, scholars have developed a wide array of theories concerning the rationale and outcomes of workplace diversity, each with its own logic and merit. Overall, these theories paint a complex image of diversity that is characterized by noble aspirations and messy realities. As far as aspirations, many organizations are genuinely motivated to build a diverse and inclusive workforce and invest a significant amount of resources in diversity management programs. As a result, organizations have seen positive changing norms such as endorsement of egalitarian attitudes and a sharp decline of overt expressions of prejudice toward socially disadvantaged groups (Dovidio \& 
Gaertner, 2000). Indeed, diversity bears the image of a "conquering hero" for its advantages in problemsolving, creativity, innovation, customer service quality, job satisfaction, increased company performance, and decreased litigation expense (Dezsö \& Ross, 2012; Galinsky et al., 2015; Herring, 2009; Paustian-Underdahl, Walker, \& Woehr, 2014; Talke, Salomo, \& Kock, 2011).

Nevertheless, there is a dark side of diversity that has not gone unnoticed. Despite the tremendous institutional commitment and financial investment, the real success of diversity effort is very limited to date (Dobbin \& Kalev, 2016). The rising positive rhetoric fails to overcome the systematic disadvantages minorities experience at the workplace while at the same time alienates the dominant white male workforce (Dover, Major, \& Kaiser, 2016). Empirical data present a dismal picture of diversity outcomes in organizations: most conventional diversity programs are not effective, and some have even inadvertently deepened workplace discrimination (Dobbin, Schrage, \& Kalev, 2015). Women, minorities, and other non-dominant group members remain underrepresented in prominent organizational positions (Dobbin \& Kalev, 2016). These findings cast doubt on the effectiveness of diversity management. Therefore, the flip side of diversity is an "insidious villain" that leads to miscommunication, conflict, disintegration, withdrawal, perceived injustice, suppressed voice, and competitiveness (Bassett-Jones, 2005). Rarely is a management imperative so beleaguered by its trials and triumphs simultaneously. Such discord between noble aspirations and messy realities call for reflection and investigation.

This article takes a cognitive perspective (Kahneman, 2003; Kahneman \& Frederick, 2002; Kahneman, Knetsch, \& Thaler, 1991; Kahneman \& Tversky, 2013) to explore the hidden obstacles to diversity management. The study of diversity is a core issue for management theory and practice, although it has been more frequently addressed in the domain of human resources (HR) due to its relevance to HR practices such as selection, promotion, and compensation. The proposition is that organizations must factor in the hidden biases embedded in human judgment in their policy-making so that they can manage the change without inadvertently eliciting resistance from the workforce. The irony of diversity management is that it sets out to address the workplace inequality due to individual differences, yet its theories and policies treat people as if they live in a social vacuum, leaving the very nature of human thinking and feeling unaddressed. Therefore, the goal of this research is to bring the central actor, people, back into the study of workplace diversity by understanding the nuances of human cognition and judgment. Key to such a change mechanism is design thinking, a cognitive approach to creating work contexts by recognizing human attributes, instead of ignoring them (Beshears \& Gino, 2015; Bohnet, 2016; Kahneman, 2011; Thaler \& Sunstein, 2008).

\section{LEWIN'S MODEL OF FORCE FIELD FOR CHANGE}

\section{Lewin's Force Field Model}

Lewin (1951) views organizational change as the result of a dynamic balance, or equilibrium, of forces working in opposite directions. Driving forces attempt to promote change while restraining forces stand to maintain the status quo and, as such, make the implementation of change difficult. For a change to occur, or the level of performance to improve, the driving forces must exceed the restraining forces, thus shifting the equilibrium. Furthermore, due to the dynamic nature of the equilibrium, just adding a driving force toward change often produces an immediate counterforce that strengthens to maintain the equilibrium. Therefore, the most profound insight of Lewin's force field model is that, while it is natural for organizations and managers to believe in the power of increasing driving forces, change can take place relatively easily by diminishing restraining forces since driving forces are usually already in the system.

Applying Lewin's (1951) force field model to human behavior, organizational psychologist Edgar Schein (1996) notes that, for behavior to change, the force field upon which the "quasi-stationary equilibria" of human behavior resides, has to be altered under complex psychological conditions. Human change, as Schein (1996, p. 60) notes, "was a profound psychological dynamic process that involved painful unlearning without loss of ego identity and difficult relearning as one cognitively attempted to restructure one's thoughts, perceptions, feelings, and attitudes." Schein's (1996) theory emphasizes that 
psychological conditions for individual perceptions and feelings must be altered to induce behavioral change.

\section{The Force Field of Diversity Management}

Diversity management represents one of the fundamental changes in modern society and has been propelled by public policies and programs. Given its root in the civil rights movement and legal mandate such as the Equal Employment Opportunity law, diversity management has been propelled by the notion of justice, legal compliance, and conscious choice (Humphries \& Grice, 1995). The most cited three rationales for diversity include strategic significance ("diversity makes good business sense"), moral and ethical reasoning ("it is the right thing to do"), and the fast increase of women and members of minority groups in the workplace ("diversity is destiny"). All these theories share a common assumption of rational choice and long-term vision for an ideal future and that individuals ought to behave accordingly. Yet, an extensive review of the diversity literature reveals that these rational arguments to promote workplace diversity are either not well received by individuals, or even raise resistance (Kalev, Dobbin, \& Kelly, 2006).

As noted by Lewin (1951), it is natural for organizations and managers to believe in the power of increasing driving forces. This misplaced tendency penetrates the way organizations manage their diversity efforts. Schein (1996) asserts that implementing behavioral change is extremely difficult because the restraining forces entail psychological defenses or group norms embedded in the organizational context. The rational reasoning for diversity can be useful in changing attitudes and generating good intentions; however, they are trivial and superficial compared to the profound psychological and cognitive process required to change behavior (Lewin, 1951). Identifying restraining forces requires looking at the situation from an individual's point of view, understanding individual thoughts, perceptions, feelings, and attitudes in the change process. In this sense, the question we should ask is not why people should accept diversity or what to do to make them accept diversity. Instead, we should be asking why it is that people are resistant to diversity and what kind of environment we can create to make it easier for people to take the right action. To answer these questions, we turn to literature in behavioral economics that explains the role of perceptions, judgments, and choices in individual behaviors.

\section{TWO SYSTEMS OF THINKING AND DIVERSITY}

\section{Two Systems of Thinking: Intuitive Judgment Versus Rational Reasoning}

Extant literature in behavior psychology (Kahneman, 2011) and behavioral economics (Thaler \& Sunstein, 2008) show two systems of thinking, intuition and rationality, are involved in the process of judgment and decisions (Kahneman, 2011). Kahneman and colleagues label them as System 1 (intuition) and System 2 (rationality). These two cognitive functions "work in tandem" when people form judgments and solve problems (Kahneman, 2011). Intuitive thinking (System 1) is instinctive, fast, happens automatically and effortlessly, and is often emotionally charged. It relies on heuristics, experience, associative or sometimes emotional tools and is extremely context-dependent. They are also governed by habit and are, therefore, difficult to control or modify (Kahneman, 2011). System 1 thinking enables people to make quick assessments based on highly sophisticated mental shortcuts and reference to experience and knowledge. It also tends to focus on concrete, immediate payoffs and distract us from the abstract, long-term consequences of the decisions (Kahneman, 2011). In this mode of thinking, knowledge is self-evident. As such, intuitive thinking resembles that of a "storyteller" whose goal is to tell a cohesive and satisfying narrative (Schaller, 1994, p.55).

In comparison, rational reasoning (System 2) is deliberate, logical, slow, conscious, and effortful. It follows a sequential process by creating and testing options with prior knowledge, assessing the relevance of various information before reaching a decision. In this cognitive process, knowledge requires justification via logic and evidence (Kahneman, 2011). This mode of thinking is also relatively flexible and potentially rule-governed. As such, rational thinking is one of a "scientist" whose goal is to "uncover 
the formal systematic structure of truth" (Schaller, 1994, p.55). System 2 thinking can correct poor snap judgments by informing us when our intuition and emotions derail our judgment. However, engaging System 2 requires exerting cognitive effort, which is a scarce resource (Kahneman \& Frederick, 2002).

These two systems of thinking explain why people can reason well but often act intuitively based on the context. Decisions in modern society can be far-reaching with large implications. Situations often demand one or the other, and people are not generally very good at using the right one or balancing the use of both methods. Because the overall capability for System 2's deliberate mental effort is limited, most judgments and choices are made intuitively. While intuition is indispensable to our sense-making and can serve us well, at times, it can lead to severe and systematic errors (Tversky \& Kahneman, 1974). In view of this, Kahneman (2003, p.1470) concludes that separation between rational belief and intuitive preference in analyses of judgment and decision making is "psychologically unrealistic." Their research implies that social context plays a major role in individual choice and decisions. Therefore, instead of trying to change minds, it is more effective to create the type of environment that factors in cognitive biases and steer people to good choices without taking away their freedom of choice (Thaler \& Sunstein, 2008).

\section{Cognitive Biases and Diversity Management}

The two-system model of human cognition provides a useful framework for us to identify a missing link in diversity management. It is widely acknowledged that contemporary forms of discrimination are subtler than the overtly prejudicial behaviors of the past (for a review, see Dipboye \& Colella, 2005). Stereotyping and social categorization function in automatic cognitive processes that are governed by intuitive thinking (Tversky \& Kahneman, 1974); however, our recognition of its role in diversity management is only assumed at this point but not understood.

One problem researchers have noted in recent years is that often, despite the best of intentions, efforts at improving diversity and inclusiveness falter and even backfire (Dobbin \& Kalev, 2016; Dover et al., 2016). The culprit behind these failures has been identified as subtle discrimination, which is commonly associated with implicit biases. Implicit biases are social stereotypes about various social and identity groups that stem from one's tendency to organize social worlds by categorizing (Greenwald \& Banaji, 1995). These biases mostly form and operate outside one's conscious awareness and therefore prove to be persistent and elusive. Nonetheless, the detrimental effect of subtle discrimination is not any less than overt discrimination in the workplace. The meta-analysis by Jones, Peddie, Gilrane, King, and Gray (2016) reviews 90 studies of the relationships between discrimination and individual and performance outcomes such as career success and satisfaction, stress, turnover, performance, and physical and mental health symptoms. Findings confirm that, across every work outcome, the effects of subtle discrimination are at least as bad, if not worse than, overt discrimination.

As mentioned earlier, for a long time, diversity management has been dominated by theories about economic incentives, rule-making, and the regulation of behavior. An epitome of this research is illustrated by Page's (2007) article, which makes a compelling case for diversity with elegant logic and convincing economic rationale. Indeed, ample evidence shows that diverse groups are more effective in solving problems and making predictions than their homogeneous counterparts based on principles of mathematics, computer science, and economics.

Until recent years, researchers have observed that economic incentives and political mandates can be counterproductive. Corporate practices intended to quell discrimination have frequently activated it (Bassett-Jones, 2005; Burrell; Dobbin, Schrage, \& Kalev, 2015; Duguid \& Thomas-Hunt, 2015). Given that most judgments and choices are formed intuitively, rational models of human behavior are psychologically unrealistic (Kahneman \& Frederick, 2002). Rational reasoning is generally good at changing people's knowledge and beliefs but not so good at changing long-term behavior. That partially explains why while society and organizations have observed a positive climb of explicit attitudes toward diversity since the beginning of the Civil Rights movement, unfavorable implicit attitudes such as stereotypes still persist (Kalinoski et al., 2013). 
In contrast, restraining forces are psychological, intuitive, operate at the individual level with the current context in mind, are on-going, and exert an impact on behavior directly. Their forces in determining behavior are much more powerful than rational reasoning. Below we will discuss five cognitive biases that bear significant implications in the diversity context.

\section{COGNITIVE ROADBLOCKS TO DIVERSITY}

\section{Roadblock One: Judgment Heuristics and Stereotypes}

Judgment heuristics, such as representativeness, availability, and anchoring heuristics, map out the cognitive underpinnings of stereotypes. Representativeness bias happens when people use categories to make judgments and draw conclusions. Availability bias refers to the tendency that people give more weight to the information that they can easily recall and hence overestimate the likelihood of an event. Anchoring effect refers to people's tendency to be heavily influenced by the initial information they receive (Kahneman, 2003). Stereotypes about social groups represent the fundamental expectations we have about others and are used to determine interpersonal judgments and behavior (Stangor \& Lange, 1994). Studies show that humans default to organizing each other by gender, race, age, and other demographic and social characteristics and then use stereotypes to create, define and perpetuate social and organizational norms (Stangor \& Lange, 1994). As a cognitive function, stereotypes help us organize, simplify, and make sense of a myriad of information encountered in our daily lives. Unfortunately, this process is often unfairly detrimental to the person being judged.

Traditional organizational roles, especially those in more powerful professions and positions, have been long anchored in a white male prototype. The anchoring effect of gender role is vividly captured by the famous case study "Heidi Roizen" in which graduate students (both women and men) read two identical profiles of a silicon value venture capitalist with the name "Heidi" or "Howard." While all participants perceive both to be competent and successful, more participants like and are willing to work for "Howard." In this case, assertiveness, success, likeability, and leadership are coherent for "Howard," but not so much for "Heidi" (McGinn \& Tempest, 2000). The literature has documented ample evidence that gender stereotype significantly explains the underrepresentation of women in leadership positions (Brescoll, 2016).

The in-depth interview study conducted by Pager and Karafin (2009) raises alarming implications about race stereotypes among hiring managers in organizations: employers with positive or non-negative experience between black and white workers nevertheless maintain strong negative attitudes about black men in general. The authors conclude that "to the extent that these attitudes shape hiring decision, even in the scenario of equal productivity among black and white workers, we would expect the problems of hiring discrimination to persist well into the future" (Pager and Karafin 2009, p. 90). These studies cast serious doubts about the effectiveness of typical diversity programs designed to treat diversity as a rational choice.

Kahneman (2003) explains that, when encountering complex tasks of assessing probabilities of an event and predicting the value of choice, people rely on heuristics principles to reduce the complex tasks to simpler judgmental operations. Social interactions are inherently associated with uncertainty and ambiguity, and people turn to these heuristics, or rules of thumb, as a substitution for complicated assessment tasks. The point is, our tendency to draw a causal conclusion based on implicit association makes us prone to stereotypes and discrimination, often without our own recognition. As such, unconscious, associative biases are particularly difficult to combat because individual people themselves do not set out to act in discriminatory ways.

\section{Roadblock Two: Loss Aversion and Status Quo Bias}

Loss aversion refers to our tendency to prefer avoiding losses to acquiring equivalent gains. According to Kahneman and Tversky (2013), we are happy when we gain something, but more than twice as unhappy when we lose it. People naturally gravitate toward the short-term reward and against longterm reward or perceived low reward. This notion means threats are evaluated more severely than 
opportunities in novel situations. The often-cited financial incentive rationale depicts diversity as a costsaving strategy. This reasoning has few effects on people's motivation and can undermine the real reasons for embracing diversity.

Due to loss aversion, people significantly discount long-term gain and use short-term costs and benefits to dominate decision-making. Studies show that people believe that diverse teams breed greater conflicts than they actually do and, as a result, receive reduced resource support (Lount Jr, Sheldon, Rink, $\&$ Phillips, 2015). Therefore, the dilemma of diversity is that the way it works may seem counterintuitive: diversity is beneficial to decision making because of the debate and unfamiliarity that it brings into the thinking process. To reap the benefit of diverse input, leaders and employees need to invite and embrace the discomfort that comes with it. Individual minds, however, do not operate on the long-term benefits or gain. Loss aversion tendency results in status quo bias, that is, when facing the novelty or complexity that is often common in the diverse work environment, our minds go with the default condition in pursuit of stability, protection, and comfort, and forgo the remote economic gain (Samuelson \& Zeckhauser, 1988).

\section{Roadblock Three: Affective Heuristic and Resistance to Mandatory Change}

The affect heuristic represents a reliance on good or bad feelings experienced related to a stimulus (Slovic, Finucane, Peters, \& MacGregor, 2007). This means feelings play an informational role in helping people to decide between choices (e.g., refusal to fly due to severe anxiety about air travel). Affect-based evaluations are quick, automatic, and rooted in the experiential thought that is activated before reflective judgments. They normally diverge from what individuals would objectively consider the best course of action. Affect-based judgments are also more pronounced when people do not have the resources or time to reflect (Slovic et al., 2007).

Traditional cost-benefit models do not take into account the psychological effect of a good feeling. One manifestation of the affect heuristic is that options that have no downside (no cost) trigger a more positive affective response, which reinforces status quo bias (Slovic et al., 2007). Many organizations approach diversity as a strategic mandate with the attempt to jump-start the action and project the commitment from the top executives. Such an institutional mandate, however, produces no positive effect of increasing the proportion by women and minorities in managerial positions (Dobbin et al., 2015). People often resent mandatory training with anger and resistance; some even develop more animosity toward minority groups afterward (Dover et al., 2016). Without manager and employee buy-in, diversity training becomes a checkbox (Dobbin \& Kalev, 2016). Consequently, diversity practices in most organizations turn into symbolic public commitments to equal opportunity and defensive legal responses to discrimination complaints. To the extent that diversity is viewed as something to be "tolerated" instead of "celebrated," it evokes negative feelings in managers and employees and thus creates more resistance toward such effort instead of promoting the course.

\section{Roadblock Four: Framing Effect of Negative Message}

The framing effect describes the situation in which people react to a particular choice in different ways depending on how it is presented. In their well-intentioned desire to highlight important issues, organizations can sometimes inadvertently communicate that the problem is relatively widespread. This action signals to people that, even if we do not like or approve of such practice, many other people and organizations are doing it (Cialdini et al., 2006). Diversity efforts involve a lot of high profile discussion of the prevalence of prejudice and discrimination in society and organizations. The assumption is that, when people realize that biases are widespread, they will be more likely to overcome them. In reality, it leads to the perception that stereotypes are common and socially acceptable behavior. Consequently, overly enthusiastic emphasis on the prevalence of prejudice and discrimination can inadvertently reinforce a negative social norm (Duguid \& Thomas-Hunt, 2015). The result can be an increase in problematic behavior. In view of this, Grant and Sandberg (2014) stress that a better method is to explicitly disapprove stereotypes and to take actions to combat them. 


\section{Roadblock Five: The Intention-Behavior Gap}

Changing behavior is different from changing people's intentions, beliefs, or attitudes (Beshears \& Gino, 2015). Norms and attitudes often shape our behaviors but not necessarily directly or in ways that we might expect, especially when the change is not intuitively desirable, or is challenging in action. Scholars have observed that the gap between the reported behavioral intention and the actual behavior in the field of social responsibility and environmental protectionism is considerable (Milkman, Rogers, \& Bazerman, 2008). Similarly, research in race relations has found a significant gap between what people say they believe about equality and how they act in practice (Asquith \& Bristow, 2000).

In the field, diversity training in organizations is mostly designed to raise employee consciousness about the legal ramifications of discrimination and immorality of prejudices. Although consciousness training is likely to alter the display of prejudices, underlying negative stereotypes tend to remain unchanged. Research shows that stereotypes are extremely resistant to change (Schaller, Asp, Roseil, \& Heim, 1996). Exposure to norms and rules alone is not sufficient to alter people's perceptions and judgments, let alone actions. Studies have uncovered a persistent discrepancy between espoused values and subconscious beliefs in employees (Asquith \& Bristow, 2000; Brigham \& Richardson, 1979). This situation highlights the importance for organizations to focus on, and objectively test, what drives people's behavior and to be cautious using associated intentions or attitudes as a measure of success for diversity programs.

\section{Summary: Mapping Bounded Rationality in Diversity Management}

Herbert Simon (1991) proposes bounded rationality as an alternative realistic decision-making model instead of the classic rational decision-making model. Bounded rationality states that when individuals make decisions, their rationality is limited by their cognitive ability and the information and time available to make the decision. Kahneman and colleagues' research provides a mapping for bounded rationality that identifies various systematic perceptual biases and judgment errors in thinking. Rational choice taxes cognitive resources. In processing large amounts of information, cognitive biases such as prejudice and stereotyping tend to prevail. Numerous empirical studies show that discrimination and biases are hardwired in organizational behavior. For example, pro-diversity statements encourage job applicants to let their guard down and disclose more racial information but end up exposing minorities to greater discrimination by organizations that have not adequately addressed discriminatory hiring practices (Kang, DeCelles, Tilcsik, \& Jun, 2016). In a study of professional hiring practices, Rivera (2012) examines how people understand and evaluate the merit and finds it to be a moving target. She notices that stereotypes serve as an unconscious navigational system guiding interviewers' attention to the clues that they see fit. As Castilla and Benard (2010) demonstrate in their well-known research on "the paradox of meritocracy," organizations with meritocratic values are often the worst offenders of bias due to the implicit nature of bias. Even though leaders proclaim a commitment to fairness in their organizations, stereotypes still lead them to evaluate and treat equal performers differently.

Facing the challenges, researchers conclude that the practice of diversity management needs to be changed radically (Dobbin et al., 2015; Kochan et al., 2003). Because formal organizational policies and practices depend on managerial implementation, it is critical to understand the nuances of human cognitions in managing workforce diversity. Given the scope and complexity of the modern work environment, judgments based on natural heuristics, intuition, and emotions have inherent weaknesses. Sound judgments need people to be effective in using the right one or balancing the use of both thinking models. Research in behavioral economics strongly suggests that, for organizations and leaders to bring the best out of their employees, it is critical to design the work context in such a way as to remove the obstacles that hinder motivation and productivity. Their argument is consistent with Lewin's logic for reducing restraining forces in the change process. Below we will introduce the behavioral design approach and discuss how these behavioral insights can be applied to benefit workplace diversity management. 


\section{BEHAVIORAL DESIGN AS A CHANGE STRATEGY}

Behavioral design is a behavioral economics approach that applies a scientific understanding of human behavior to design policy interventions. Developed based on the pioneering work of Kahneman and Tversky (2013), behavioral design believes that better judgment and decision making can be achieved through "choice architecture," the process of altering the environment in which decisions are made (Thaler \& Sunstein, 2008). Choice architecture, often dubbed as the "nudge" approach, has proven to be an effective tool in balancing the use of System 1 and System 2 thinking. A nudge is "(a)ny aspect of the design of a choice ("choice architecture") that alters people's behavior in a predictable way, without forbidding anything or actually changing the choice at all" (Thaler \& Sunstein, 2008). The behavioral design approach acknowledges the reality of individuals and situations (Milkman et al., 2008). Specifically, individuals have certain attitudes, knowledge, and experience that are unique to them, and these traits and tendencies are mostly stable and consistent over time. The effective behavioral design allows choices but designs choices in a way that enables focus on the right things and making meaningful evaluations (Thaler \& Sunstein, 2008).

A behavioral design removes restraining forces by creating the context that induces positive behavior naturally. It does so by working with human nature, not against it. Overcoming System 1 shortcuts requires emotional intelligence and social competency. This is difficult to achieve at the mass level. But organizations and leaders have the power to design the work context in a way to reduce individual cognitive load and mitigate biases (Beshears \& Gino, 2015; Bohnet, 2016; Thomas \& Ely, 1996). Beshears and Gino (2015) suggest, that instead of trying to rewire the human brain, which is extremely difficult, organizations can deliberately set the stage and make it easier for people to reach more-rational decisions. We suggest five insights that are particularly relevant for diversity management and provide propositions accordingly.

\section{Insight One: Allow Choices but Motivate Good Choices}

A fundamental psychological principle established in motivation literature is that choice and autonomy lead to engagement and performance; an effort to coerce people's views and choices often results in rebellious actions in their attempt to assert autonomy and self-validation (Gagné \& Deci, 2005). The widely cited Dobbin et al. (2015) study of human resource practices on managerial diversity analyzes three decades' worth of data from 816 U.S. workplaces and conducts in-depth interviews with hundreds of line managers and executives. The study finds that popular diversity mandates intended to reduce bias and increase diversity inadvertently make matters worse. These popular institutionalized control tactics, including mandatory diversity training, job test, and grievance systems, threaten managers' autonomy, elicit resistance from managers, and motivate them to rebel against rules.

In contrast, management practices, some not even designed as diversity interventions, such as mentoring programs, self-managed teams, and task forces, boost diversity in businesses. The authors conclude that companies can get better results when they ease up on control tactics. Various employmentrelated practices are subject to managers' discretion. The key is to engage managers in solving the problem, increase their on-the-job contact with the female and minority workers, and promote social accountability.

Based on their research, Dobbin and colleagues identify a few behavioral designs that can improve diversity outcomes. Self-managed teams allow people in different roles and functions to work together on projects as equals. A positive experience leads to a positive attitude toward diversity. Rotate-training allows people to try their hand at various jobs and deepen their understanding of the whole organization. Transparency activates social accountability, creating an endowment effect that leads to true commitment (Dobbin \& Kalev, 2016). These practices are highly compatible with the suggestions of behavioral insights, and thus provide valuable input for organizations.

Proposition 1: Decision autonomy that motivates good choices by managers will have a positive impact on diversity management. 


\section{Insight Two: Structure Complex Choices}

Complexity often leads to mindless choices because they tax people's rational thinking (Kahneman, 2003). Since social categorization is mostly an implicit process stemming from intuitive thinking, companies can reduce ambiguity and subjectivity through well-defined procedures. Furthermore, companies can harness the power of default and turn status quo bias into an advantage through wellestablished procedures and practices. Some of the most famous policy examples from the behavioral economics literature relate to redesigning the default options (Thaler \& Sunstein, 2008). In diversity research, scholars (Johnson, Hekman, \& Chan, 2016) find that one woman candidate in the finalist candidate pool for professional hiring confirms stereotypes; however, having at least two women in the finalist candidate pool increases the chance of the hiring team selecting a woman dramatically. The authors conclude that good default choice architecture helps companies not only mitigate false assumptions but can encourage them to make more egalitarian decisions.

In another study, Bohnet, van Geen, and Baxerman (2016) address gender diversity with joint evaluation in hiring processes. Specifically, their experiments show that joint evaluations (hiring in bundles) as compared to single evaluation (hiring one at a time sequentially) affect the choices people make. In the joint evaluation process, people focus attention on more objective criteria such as past performance as compared to stereotypical judgments. Klein, Knight, Ziegert, Lim, and Saltz (2011) compare the impact of task-focused leadership vs. person-focused leadership on task performance in teams high in values diversity. Task-focused leaders deliver clear, structured direction, define roles and responsibilities, and specify instructions, tasks, and required deliverables. Person-focused leaders closely attend to individual team members' unique and differing perspectives, show warmth, and encourage participation. Findings show that, when dealing with high-value diversity, task-focused leadership has the advantage of reducing conflict and enhancing team effectiveness, and person-focused leadership behaviors exacerbate team conflict. These findings highlight the importance of well-defined organizational procedures and leadership styles that can facilitate diversity management.

Proposition 2: Organizational procedures and leadership styles that remove ambiguity and subjectivity in the decision making process will have a positive impact on diversity management.

\section{Insight Three: Frame Positive Conversation}

Decision-making requires the interpretation and evaluation of information. Because the way information is framed and communicated influences how people judge, organizations need to be mindful of the way they create a conversation about diversity. Unfortunately, the majority of the diversity talks in the past frame it in a negative light. Many companies highlight the legal and financial damage of discrimination as a reason for diversity. Many programs describe training as remedial, implying managers as the worst culprits (Dobbin \& Kalev, 2016). This type of framing of messages forces people into a defensive position and can activate bias. Lowery and Wout (2010) experimented with the framing of inequality among white and minority students in the academic domain. They found framing inequality regarding white advantage had more positive consequences for African American and Latino students' academic engagement than when framing inequality regarding minority disadvantage. Such a framing directed their sense of self more toward to their academic performance. However, the same white advantage frame was disengaging for white students due to the same psychological mechanism (Lowery $\&$ Wout, 2010). The scholars further replicated the effects of inequality framing in business and societal contexts (Lowery, Chow, Knowles, \& Unzueta, 2012). Research like this not only highlights the power of framing but also pinpoints the nuances of perceptions among different social groups.

Furthermore, consistent with the phenomenon of attribute substitution where people substitute complex judgment tasks with easy heuristics (Kahneman \& Frederick, 2002), the concept of diversity has been trivialized to be a few dichotomies - male/female, white/black, dominant/minority, and so on.

People are a multifaceted, multilevel, dynamic bundle of preferences, decisions, and behaviors. It is hard to generalize about any group of people. Talking about diversity in categories trap people in a box and will only deepen stereotypes and divides. Therefore, companies need to integrate diversity into the 
organizational process and use diversity as a means for looking at, identifying, developing, and advancing talent so that diversity practice will become relevant.

Proposition 3: Framing diversity as part of talent management in the organizational process will have a positive impact on diversity management while framing diversity as narrow identity management will have a negative impact on diversity management.

\section{Insight Four: Use Training to Improve Cognitive Ability}

The dual-process model of thinking helps us understand that one of the causes of group stereotypes is people's failure to engage in sophisticated logical thinking. Kahneman (2003) suggests that interventions that enhance the need for cognition and attributional complexity can reduce the motivation to simplify and structure the environment and thus reduce implicit biases. A scientific reasoning orientation can help correct poor snap judgments by informing us when our intuition and emotions derail our judgment (Beshears \& Gino, 2015). Given that people are "intuitive statisticians" (Schaller et al., 1996), those who receive training in logical/statistical thinking are more likely to apply statistical concepts when drawing inferences and making judgments (Lehman, Lempert, \& Nisbett, 1988).

For example, the well-known "fundamental attribution error" is the tendency for people to place an undue emphasis on personal characteristics when making attributions about someone else's behavior without fully considering the situational constraints; however, people do not interpret their own behavior with this tendency because they can easily recognize situational factors and, thus, take them into consideration (Ross, 1977). Empirical studies show that exposure to unbiased demographics and information alone is not enough to alter stereotypes regarding ethnic groups (Pager \& Karafin, 2009). Studies of cognitive training show that training in statistical reasoning can be effective at reducing erroneous stereotypes (Schaller et al., 1996), however. For example, training in the logic of statistical analysis of covariance (ANCOVA) is shown to lead to enhanced accuracy of the group impressions that people form (Schaller et al., 1996; Schaller \& O'Brien, 1992). While this does not mean that diversity training has to turn into statistical boot camp, it does suggest a few benefits of enhanced ability for logical inference. They make people more cautious, more skeptical of their own initial impressions, and enhance the likelihood of actually detecting and "partial it out" confounding factors when arriving at group impressions (Schaller \& O'Brien, 1992).

Recent diversity training has expanded on unconscious bias training. While unconscious bias training can help employees and leaders become aware of their perceptual inefficiency and biases, cognitive ability training can help improve judgment objectivity. Research suggests that the majority of discrimination is not due to animus but represents statistical discrimination (List, 2004). Training that fosters managers' abilities to engage in sophisticated cognitive reasoning can equip them with mindful thinking tools and allow them to make more accurate judgments.

Proposition 4: Training in scientific reasoning to reduce implicit biases will have a positive impact on diversity management.

\section{Insight Five: Expect Error}

Where rational judgment models assume that individuals will update and refine their beliefs by incorporating new information, social-psychological models emphasize the cognitive resistance to information that is disconfirming of expectations (Goodwin, Operario, \& Fiske, 1998). A wealth of experimental evidence supports the psychological view by illustrating that individuals subconsciously refuse to accept disconfirming information that does not conform to their stereotypes. Instead, they allow group stereotypes to remain intact by creating a subtype of the group, treating the non-stereotype conforming information as exceptions, unrepresentative of the group as a whole (Taylor, 1981; Weber \& Crocker, 1983). Stereotypes about groups, in particular, unfavorable racial attributions, do not recede even when people are confronted with rebutting information or exposed to competing experience (e.g., Asquith \& Bristow, 2000; Pager \& Karafin, 2009). This enduring cognitive tendency partially explains 
why efforts to eradicate discrimination in the workplace and society have only been met with marginal success.

Modern discrimination is mostly manifested as subconscious biases and hidden prejudices rather than overt racism beliefs (Greenwald, McGhee, \& Schwartz, 1998). It is difficult for people to change their behavior if they do not recognize their biases and are unwilling to correct their perceptions. This requires organizations to make long-term commitments to acknowledge the enduring power of human psychology and create a positive learning experience for behavioral change.

Proposition 5: A long-term commitment that creates an ongoing learning process will have a positive impact on diversity management.

\section{CONCLUSION}

This article contributes to the diversity literature by introducing the cognitive foundation for diversity management. From a change perspective (Lewin, 1951), this paper explains how cognitive biases can turn into restraining forces against organizational efforts to promote diversity and inclusion. The juxtaposition of Lewin's force field model and the dual-process thinking model offers a plausible explanation for the gap between the aspiration and reality of diversity management. We then propose a behavioral design approach to promote workplace diversity by addressing the cognitive roadblocks and designing the work context to reduce cognitive barriers. This approach has the potential to help organizations shift the equilibrium toward to new higher ground of diversity. A behavioral design approach provides a new useful lens to examine the restraining forces not captured by existing diversity theories and holds practical promise for generating positive outcomes.

Demographic and cultural diversity in modern workplaces adds much complexity for behavioral management. As with many other changes that challenge our sense-making, diversity is often not an intuitive choice for individuals. As individuals, we tend to gravitate to people who are like us as similarity renders us an intuitive sense of psychological security, social validation, and predictability (Byrne, 1969). Unfortunately, such a tendency affects women and minorities to a greater extent at the workplace, given that the majority of the workforce has historically been made up by white males.

To the extent that social and organizational systems are designed to be rational and consistent, and human psychology is not, our personal judgments and social experience are bound to come into conflict. In the past, diversity research has generally assumed that individuals' perceptions of diversity are accurate, consistent with normative theories of judgments in economics. Traditional models for diversity management do not account for the systematic effect of cognitive bias in determining behavior. While it is necessary for us to disavow prejudice and discrimination in the workplace, abandoning stereotypes takes more effort than rational reasoning (Dovidio \& Gaertner, 2000). Reality has challenged this assumption with empirical data showing that most diversity programs are not effective (Kalev et al., 2006). Because unconscious bias is far more prevalent than conscious prejudice, diversity programs that hope to make a real difference need to go with the flow of human cognitive processes rather than forcefeeding attitudes and behavior (Beshears \& Gino, 2015).

Behavioral design differs from a conventional mandate in that it allows organizations and leaders to incorporate the cognitive biases or motivational deficiencies in the design of the work context. The focus is to align personal preferences with organizational systems through incremental behavioral changes without taking away individual choices. Individual differences notwithstanding, people are generally responsive to social learning mechanisms. A few principles that emerge from the field of behavioral economics can facilitate organizational diversity agenda. First, organization-wide systems and processes are more effective in mitigating the negative effects of implicit bias than a rational mandate. Second, diversity practices, policies, and programs should be designed to reflect our best understanding of human psychology. Third, diversity programs, like all business programs, should be tested and validated (Beshears \& Gino, 2015; Dobbin \& Kalev, 2016). 
It is important to emphasize that behavioral design is not meant to replace the institutional effort for diversity and inclusion. Rather, it provides us with a useful tool with a realistic mindset to bridge human psychology with the work context (Milkman et al., 2008). Scholars describe the dilemmas between aspiration and reality in the quest for workplace diversity as "tidy logic, messier realities" (Klein \& Harrison, 2007). The fact that discrimination is diehard might be in part due to its root in our very own cognition. It is time to bring people back into the study of diversity management with a nuanced understanding of human cognition (Castilla, 2011).

\section{REFERENCES}

Asquith, J. A. L., \& Bristow, D. N. (2000). To catch a thief: A pedagogical study of retail shoplifting. Journal of Education for Business, 75(5), 271-276.

Bassett-Jones, N. (2005). The paradox of diversity management, creativity and innovation. Creativity and Innovation Management, 14(2), 169-175.

Beshears, J., Choi, J. J., Laibson, D., Madrian, B. C., \& Milkman, K. L. (2015). The effect of providing peer information on retirement savings decisions. The Journal of Finance, 70(3), 1161-1201.

Beshears, J., \& Gino, F. (2015). Leaders as decision architects. Harvard Business Review, 93(5), 52-62.

Bohnet, I. (2016). What works: Gender equality by design. Harvard University Press.

Bohnet, I., van Geen, A., \& Baxerman, M. (2016). When Performance Trumps Gender Bias: Joint vs. Separate Evaluation. Management Science, 62(5), 1225-1234.

Brescoll, V. L. (2016). Leading with their hearts? How gender stereotypes of emotion lead to biased evaluations of female leaders. The Leadership Quarterly, 27(3), 415-428.

Brigham, J. C., \& Richardson, C. B. (1979). Race, sex, and helping in the marketplace. Journal of Applied Social Psychology, 9(4), 314-322.

Burrell, L. (2016). We just can't handle diversity. Harvard Business Review, 94(7), 70-74.

Byrne, D. (1969). Attitudes and attraction. Advances in Experimental Social Psychology, 4, 35-89.

Castilla, E. J. (2011). Bringing managers back in: Managerial influences on workplace inequality. American Sociological Review, 76(5), 667-694.

Castilla, E. J., \& Benard, S. (2010). The paradox of meritocracy in organizations. Administrative Science Quarterly, 55(4), 543-676.

Cialdini, R. B., Demaine, L. J., Sagarin, B. J., Barrett, D. W., Rhoads, K., \& Winter, P. L. (2006). Managing social norms for persuasive impact. Social Influence, 1(1), 3-15.

Dezsö, C. L., \& Ross, D. G. (2012). Does female representation in top management improve firm performance? A panel data investigation. Strategic Management Journal, 33(9), 1072-1089.

Dipboye, R. L., \& Colella, A. (2005). The dilemmas of workplace discrimination. Discrimination at Work: The Psychological and Organizational Bases, 425-462.

Dobbin, F., \& Kalev, A. (2016). Why Diversity Programs Fail And what works better. Harvard Business Review, 94(7), 52-60.

Dobbin, F., Schrage, D., \& Kalev, A. (2015). Rage against the iron cage: The varied effects of bureaucratic personnel reforms on diversity. American Sociological Review, 80(5), 1014-1044.

Dover, T. L., Major, B., \& Kaiser, C. R. (2016). Members of high-status groups are threatened by prodiversity organizational messages. Journal of Experimental Social Psychology, 62, 58-67.

Dovidio, J. F., \& Gaertner, S. L. (2000). Aversive racism and selection decisions: 1989 and 1999. Psychological Science, 11(4), 315-319.

Duguid, M. M., \& Thomas-Hunt, M. C. (2015). Condoning stereotyping? How awareness of stereotyping prevalence impacts expression of stereotypes. Journal of Applied Psychology, 100(2), 343-359.

Gagné, M., \& Deci, E. L. (2005). Self-determination theory and work motivation. Journal of Organizational Behavior, 26(4), 331-362.

Galinsky, A. D., Todd, A. R., Homan, A. C., Phillips, K. W., Apfelbaum, E. P., Sasaki, S. J., .. . Maddux, W. W. (2015). Maximizing the gains and minimizing the pains of diversity: A policy perspective. Perspectives on Psychological Science, 10(6), 742-748. 
Goodwin, S. A., Operario, D., \& Fiske, S. T. (1998). Situational power and interpersonal dominance facilitate bias and inequality. Journal of Social Issues, 54(4), 677-698.

Grant, A., \& Sandberg, S. (2014, December 6). When talking about bias backfires. The New York Times. Retrieved from https://www.nytimes.com/2014/12/07/opinion/sunday/adam-grant-and-sherylsandberg-on-discrimination-at-work.html.

Greenwald, A. G., \& Banaji, M. R. (1995). Implicit social cognition: Attitudes, self-esteem, and stereotypes. Psychological Review, 102(1), 4-27.

Greenwald, A. G., McGhee, D. E., \& Schwartz, J. L. (1998). Measuring individual differences in implicit cognition: the implicit association test. Journal of Personality and Social Psychology, 74(6), 1464-1480.

Herring, C. (2009). Does diversity pay? Race, gender, and the business case for diversity. American Sociological Review, 74(2), 208-224.

Humphries, M., \& Grice, S. (1995). Equal employment opportunity and the management of diversity: A global discourse of assimilation? Journal of Organizational Change Management, 8(5), 17-32.

Ivancevich, J. M., \& Gilbert, J. A. (2000). Diversity management: Time for a new approach. Public Personnel Management, 29(1), 75-92.

Johnson, S. K., Hekman, D. R., \& Chan, E. T. (2016). If there's only one woman in your candidate pool, there's statistically no chance she'll be hired. Harvard Business Review, 26(4). Retrieved from https://hbr.org/2016/04/if-theres-only-one-woman-in-your-candidate-pool-theres-statistically-nochance-shell-be-hired

Jones, K. P., Peddie, C. I., Gilrane, V. L., King, E. B., \& Gray, A. L. (2016). Not so subtle: A metaanalytic investigation of the correlates of subtle and overt discrimination. Journal of Management, 42(6), 1588-1613.

Kahneman, D. (2003). A perspective on judgment and choice: mapping bounded rationality. American Psychologist, 58(9), 697-720.

Kahneman, D. (2011). Thinking, fast and slow. Macmillan.

Kahneman, D., \& Frederick, S. (2002). Representativeness revisited: Attribute substitution in intuitive judgment. Heuristics and Biases: The Psychology of Intuitive Judgment, 49, 49-81.

Kahneman, D., Knetsch, J. L., \& Thaler, R. H. (1991). Anomalies: The endowment effect, loss aversion, and status quo bias. The Journal of Economic Perspectives, 5(1), 193-206.

Kahneman, D., \& Tversky, A. (2013). Prospect theory: An analysis of decision under risk. Econometrica, 47(2), 363-391

Kalev, A., Dobbin, F., \& Kelly, E. (2006). Best practices or best guesses? Assessing the efficacy of corporate affirmative action and diversity policies. American Sociological Review, 71(4), 589617.

Kalinoski, Z. T., Steele-Johnson, D., Peyton, E. J., Leas, K. A., Steinke, J., \& Bowling, N. A. (2013). A meta-analytic evaluation of diversity training outcomes. Journal of Organizational Behavior, 34(8), 1076-1104.

Kang, S. K., DeCelles, K. A., Tilcsik, A., \& Jun, S. (2016). Whitened resumes: Race and self-presentation in the labor market. Administrative Science Quarterly, 61(3), 469-502.

Klein, K. J., \& Harrison, D. A. (2007). On the diversity of diversity: Tidy logic, messier realities. The Academy of Management Perspectives, 21(4), 26-33.

Klein, K. J., Knight, A. P., Ziegert, J. C., Lim, B. C., \& Saltz, J. L. (2011). When team members' values differ: The moderating role of team leadership. Organizational Behavior and Human Decision Processes, 114(1), 25-36.

Kochan, T., Bezrukova, K., Ely, R., Jackson, S., Joshi, A., Jehn, K., . . Thomas, D. (2003). The effects of diversity on business performance: Report of the diversity research network. Human Resource Management, 42(1), 3-21.

Konrad, A. M., Prasad, P., \& Pringle, J. (2005). Handbook of workplace diversity. Sage Publications. 
Lehman, D. R., Lempert, R. O., \& Nisbett, R. E. (1988). The effects of graduate training on reasoning: Formal discipline and thinking about everyday-life events. American Psychologist, 43(6), 431442.

Lewin, K. (1951). Field theory in social science: selected theoretical papers (Edited by Dorwin Cartwright). Harpers.

List, J. A. (2004). The nature and extent of discrimination in the marketplace: Evidence from the field. The Quarterly Journal of Economics, 119(1), 49-89.

Lount, R. B., Jr., Sheldon, O. J., Rink, F., \& Phillips, K. W. (2015). Biased perceptions of racially diverse teams and their consequences for resource support. Organization Science, 26(5), 1351-1364.

Lowery, B. S., \& Wout, D. A. (2010). When inequality matters: the effect of inequality frames on academic engagement. Journal of Personality and Social Psychology, 98(6), 956-966.

Lowery, B. S., Chow, R. M., Knowles, E. D., \& Unzueta, M. M. (2012). Paying for positive group esteem: How inequity frames affect whites' responses to redistributive policies. Journal of Personality and Social Psychology, 102(2), 323-336.

McGinn, K. L., \& Tempest, N. (2000). Heidi Roizen. Harvard Business School Case 800-228. Harvard Business School.

Milkman, K. L., Rogers, T., \& Bazerman, M. H. (2008). Harnessing our inner angels and demons: What we have learned about want/should conflicts and how that knowledge can help us reduce shortsighted decision making. Perspectives on Psychological Science, 3(4), 324-338.

Page, S. E. (2007). Making the difference: Applying a logic of diversity. The Academy of Management Perspectives, 21(4), 6-20.

Pager, D., \& Karafin, D. (2009). Bayesian bigot? Statistical discrimination, stereotypes, and employer decision making. The Annals of the American Academy of Political and Social Science, 621(1), 70-93.

Paustian-Underdahl, S. C., Walker, L. S., \& Woehr, D. J. (2014). Gender and perceptions of leadership effectiveness: A meta-analysis of contextual moderators. Journal of Applied Psychology, 99(6), $1129-1145$.

Rivera, L. A. (2012). Hiring as cultural matching: The case of elite professional service firms. American Sociological Review, 77(6), 999-1022.

Ross, L. (1977). The intuitive psychologist and his shortcomings: Distortions in the attribution process. Advances in Experimental Social Psychology, 10, 173-220.

Samuelson, W., \& Zeckhauser, R. (1988). Status quo bias in decision making. Journal of Risk and Uncertainty, 1(1), 7-59.

Schaller, M. (1994). The role of statistical reasoning in the formation, preservation and prevention of group stereotypes. British Journal of Social Psychology, 33(1), 47-61.

Schaller, M., \& O'Brien, M. (1992). "Intuitive analysis of covariance" and group stereotype formation. Personality and Social Psychology Bulletin, 18(6), 776-785.

Schaller, M., Asp, C. H., Roseil, M. C., \& Heim, S. J. (1996). Training in statistical reasoning inhibits the formation of erroneous group stereotypes. Personality and Social Psychology Bulletin, 22(8), 829-844.

Schein, E. H. (1996). Kurt Lewin's change theory in the field and in the classroom: Notes toward a model of managed learning. Systemic Practice and Action Research, 9(1), 27-47.

Simon, H. A. (1991). Bounded rationality and organizational learning. Organization Science, 2(1), 125134.

Slovic, P., Finucane, M. L., Peters, E., \& MacGregor, D. G. (2007). The affect heuristic. European Journal of Operational Research, 177(3), 1333-1352.

Stangor, C., \& Lange, J. E. (1994). Mental representations of social groups: Advances in understanding stereotypes and stereotyping. Advances in Experimental Social Psychology, 26, 357-416.

Talke, K., Salomo, S., \& Kock, A. (2011). Top management team diversity and strategic innovation orientation: The relationship and consequences for innovativeness and performance. Journal of Product Innovation Management, 28(6), 819-832. 
Thaler, R. H., \& Sunstein, C. R. (2008). Nudge: Improving decisions about health, wealth, and happiness, New Haven, CT: Yale University Press.

Thomas, D. A., \& Ely, R. J. (1996). Making differences matter. Harvard Business Review, 74(5), 79-90.

Tversky, A. \& Kahneman, D. (1974). Judgment under uncertainty: Heuristics and biases. Science, 185(4157), 1124-1131.

Weber, R., \& Crocker, J. (1983). Cognitive processes in the revision of stereotypic beliefs. Journal of Personality and Social Psychology, 45(5), 961-977. 